OPEN ACCESS

Edited by:

Jizhou Tang,

Tongji University, China

Reviewed by:

Lihua Zuo,

Texas A\&M University Kingsville,

United States

Hua Zhang,

Buckman Laboratories, United States

*Correspondence:

Xu Jin

jinxu@petrochina.com.cn

Bo Xiong

xiongb69@petrochina.com.cn

Specialty section:

This article was submitted to

Economic Geology,

a section of the journal

Frontiers in Earth Science

Received: 23 July 2021

Accepted: 24 August 2021 Published: 20 September 2021

Citation:

Zhang $C$, Jin X, Tao J, Xiong B, Pan Z, Meng $S$, Ding $B$, Wang $Y$ and Liang $L$ (2021) Comparison of Nanomaterials

for Enhanced Oil Recovery in Tight Sandstone Reservoir.

Front. Earth Sci. 9:746071. doi: 10.3389/feart.2021.746071

\section{Comparison of Nanomaterials for Enhanced Oil Recovery in Tight Sandstone Reservoir}

\author{
Chenjun Zhang ${ }^{1}, \mathrm{Xu} \mathrm{Jin}^{1 *}$, Jiaping Tao ${ }^{1,2}$, Bo Xiong ${ }^{1 *}$, Zhijian Pan ${ }^{1}$, Siwei Meng ${ }^{1}$, Bin Ding ${ }^{1}$, \\ Ying Wang ${ }^{1}$ and Lihao Liang $^{2}$
}

${ }^{1}$ Research Institute of Petroleum Exploration \& Development, PetroChina, Beijing, China, ${ }^{2}$ School of Petroleum Engineering, China University of Petroleum (East China), Qingdao, China

With dwindling conventional oil resources, the development of high-performance oildisplacing agents to exploit unconventional oil and gas resources has become a research focus, and new technical ideas have been proposed for petroleum engineering with the advancement of nanomaterials and technology. This study characterized the microscopic pore throat structure of the unconventional tight sandstone reservoir of Ordos Basin in China comprehensively by using high-resolution scanning electron microscopy, image panoramic mosaic technology, mineral quantitative scanning system, and 3D image of pore. A new nanofluid with diphenyl ether surfactants as shell and $\mathrm{C}_{10}-\mathrm{C}_{14}$ straight-chain hydrocarbon compounds as kernel was prepared according to the features of tight sandstone reservoirs. The basic physical properties of the nanofluid were evaluated and compared with those of three other generic oil-displacing agents to understand the oil-displacement effect and mechanism. Results show that this nanofluid remains relatively stable and dispersible with aging and its average particle size matches well with the pore throat size of the target reservoir, which increases the sweep volume effectively. Additionally, the change from oil-wet to water-wet can exert capillary imbibition. And the oil-water interfacial tension can be greatly reduced to the level of $10^{-2}$ $\mathrm{mN} / \mathrm{m}$ because of nanofluid's excellent interfacial activity, which improves the efficiency of oil washing in nano-scale pore throats. Finally, the core imbibition experiment further demonstrated the superiority of the nanofluid. Using the nanofluid in optimal concentration with cores of approximately $0.1 \mathrm{mD}$ can achieve a recovery rate of $37.5 \%$, which is higher than generic oil-displacing agents by up to $9 \%$. This study demonstrates that the excellent performance of nanofluid in enhancing oil recovery and provides a reference for the development of unconventional reservoirs, which are difficult to function with generic agents.

Keywords: unconventional reservoir, tight sandstone, oil-displacing agent, nanofluid, enhanced oil recovery

\section{INTRODUCTION}

As non-renewable resources, oil and gas have limited underground reserves. Due to constraints in geological conditions and development technology, most crude oil still remains underground. Various technologies for enhanced oil recovery (EOR) have gradually become important technologies for oil and gas field development. Unconventional tight oil and gas resources have 
become the main oil and gas resources for increasing reserves and production nowadays and have currently been the research hotspot in EOR and economic development. The recoverable resources of unconventional oil and gas are mainly distributed in the four major regions of North America, Asia-Pacific, Latin America, and Russia (Zou et al., 2015). The median porosity of tight sandstone reservoirs in China ranges from 3.2 to $9.1 \%$, with an average of $1.5-9.04 \%$, and a median permeability of 0.03 to $0.455 \mathrm{mD}$, with an average of 0.01 to $1.0 \mathrm{mD}$ (Zou et al., 2012). Aside from their thin pore throat structure, vast heterogeneity, strong capillary force, and non-Darcy flow, tight sandstone reservoirs have tremendously different characteristics, including oil and gas occurrence law and fluid flow mechanism, when compared with conventional oil reservoirs. Therefore, tight sandstone reservoirs are faced with the problems of rapid increase in water content, rapid decline in production, and generally low recovery factors. Generic chemical agents are difficult to sweep effectively. Thus, the development of key materials for EOR and technological innovation warrants investigation.

Various EOR methods can be considered in the initial stage to fit in unconventional reservoir conditions. Chemical flooding is an important branch of enhanced oil recovery, and its technology development has been relatively mature. Injecting chemical agents into the formation improves not only the flow characteristics of the fluid in the microscopic pores of the formation but also the interface characteristics among the oildisplacing agents, the rock surface, and the crude oil to achieve EOR. However, applying those techniques in unconventional oil reservoirs is challenging because of the different flooding theories and exploitation technologies between conventional and unconventional oil reservoirs. Among chemical flooding methods, polymers feature poor salt tolerance or high temperature resistance in oil reservoirs, high material consumption, and serious chemical loss, and they cannot drive the residual oil in small pores; alkaline flooding affects the demulsification of crude oil, causing serious scaling and formation damage; meanwhile, surfactants easily adhere to the rock surface, which increases the amount of oil-displacing agents and the cost; the application of chemical compound flooding is also limited because of the lack of high-temperature-resistance and corrosion-resistance polymers and surfactants (Jay et al., 1999; Chang et al., 2006; Muggeridge et al., 2014). Therefore, innovative research on the modification and development of oildisplacing agents is necessary in response to the above-mentioned problems.

With the further integration of nanotechnology and petroleum engineering, the application of nanomaterials in oilfield EOR has become a research focus of scientists worldwide (Fletcher and Davis, 2010; Shamsijazeyi et al., 2014; Liu et al., 2018; Zhang F. et al., 2020; Zhang L. et al., 2020; Ledyastuti and Jason, 2020; Al-Anssari et al., 2021; Keykhosravi et al., 2021). Nanomaterials are ultrafine materials with at least one dimension in the range of $1-100 \mathrm{~nm}$ in the $3 \mathrm{D}$ space (Das et al., 2008). Owing to the small particle size and large specific surface area of nanomaterials, the number of surface-active atoms, surface free energy, and interfacial tension of nanoparticles (NPs) increases sharply as the particle size decreases. Compared with generic chemical agents, nanomaterials agents have certain advantages in the aspects of rheology, wettability, surface effects, particle migration, and so on (Liu et al., 2016). The pore diameter of tight sandstone reservoirs is generally in micrometers, and nanomaterials can pass through the pores easily. Nanomaterial agents form a constitutionally stable interfacial film between the continuous phase and the dispersed phase; thus, they have strong adsorption capacity at the interface and require high energy to separate from the interface. Compared with common surfactant emulsions, nanomaterials have good stability. Therefore, in view of the development problems of tight sandstone reservoirs, the use of nano-scale chemical agents for flooding has become a new method for EOR and provides a new idea for the development of improving oil recovery.

In the past decade of research, scientists have developed many nanomaterials for oil displacement. Silica nanoparticles (SNPs) are commonly used among all nanomaterials because of their excellent dynamic and rheological properties, and many studies have shown that SNPs exert a good effect on EOR (Ju et al., 2006; Ju and Fan, 2009; Sadeghpour et al., 2013; Zhang et al., 2014). Ragab produced nanosilica of different sizes from the white sand and considered that $78 \mathrm{~nm}$ nanosilica particles coated with xanthan gum polymer could achieve the highest ultimate recovery factor of $80 \%$ (Ragab and Hannora, 2015). The stability of $\mathrm{CO}_{2}$ foam stabilized by silica and nanoclay NPs was studied and its oil recovery was investigated by performing modified bulk foam tests and flow experiments (Guo and Aryana, 2016). Dai prepared new self-dispersing SNPs, tested them by spontaneous imbibition experiment of lowpermeability cores (Dai et al., 2017), and then explained the potential EOR mechanism of silica nanofluids from the aspects of interfacial tension, contact angle, structural disjoining pressure mechanism (Wasan et al., 2011; Zhang et al., 2016, 2018), and so on. Although the interfacial tension and contact angle decrease with the increase in nanofluid concentration, Hendraningrat also found that high concentrations (e.g., $0.1 \mathrm{wt}$ $\%$ or more) of SNPs block the pore network and will not give additional oil recovery in low-permeability reservoirs (Hendraningrat, 2013; Hendraningrat and Torsater, 2014). Therefore, optimizing the nanofluid concentration can maximize the recovery factor. As for the potential agents based on metal nanomaterials, such as zirconium dioxide $\left(\mathrm{ZrO}_{2}\right)$, titanium dioxide $\left(\mathrm{TiO}_{2}\right)$, aluminum oxide $\left(\mathrm{Al}_{2} \mathrm{O}_{3}\right)$, iron oxide $\left(\mathrm{Fe}_{3} \mathrm{O}_{4}\right)$, and cerium oxide $\left(\mathrm{CeO}_{2}\right)$, their mechanism is mainly to increase the viscosity of the agents and reduce the interfacial tension between oil and water. Giraldo used alumina-based nanofluid as a wettability modifier in sandstone cores (Giraldo et al., 2013); Hamide Ehtesabi investigated the behavior of low-concentration $\mathrm{TiO}_{2}$ NPs in core plug porous media and its transport and retention in the oilfield reservoir through studying the diffusion, adsorption, and deposition of NPs in different parts of the core plug (Ehtesabi et al., 2014, 2015).

Despite all reported studies, many studies have focused on conventional oil reservoirs. There are very few experiments 
TABLE 1 | Physical parameters of cores.

\begin{tabular}{|c|c|c|c|c|c|}
\hline Core number & Length, cm & Diameter, cm & Permeability, md & Porosity, \% & $\begin{array}{c}\text { Pore volume, } \\
\mathrm{cm}^{3}\end{array}$ \\
\hline A & 5.993 & 2.528 & 0.102 & 5.894 & 1.774 \\
\hline $\mathrm{B}$ & 5.662 & 2.527 & 0.107 & 7.162 & 2.019 \\
\hline C & 5.499 & 2.498 & 0.078 & 8.437 & 2.274 \\
\hline $\mathrm{D}$ & 5.853 & 2.524 & 0.117 & 8.446 & 2.474 \\
\hline$E$ & 5.477 & 2.529 & 0.116 & 9.222 & 2.536 \\
\hline $\mathrm{F}$ & 5.837 & 2.525 & 0.033 & 5.662 & 1.655 \\
\hline$G$ & 4.752 & 2.533 & 0.087 & 7.161 & 1.715 \\
\hline $\mathrm{H}$ & 5.276 & 2.529 & 0.109 & 9.325 & 2.471 \\
\hline 1 & 6.627 & 2.535 & 0.174 & 8.639 & 2.890 \\
\hline$J$ & 6.449 & 2.514 & 0.768 & 9.769 & 3.126 \\
\hline $\mathrm{a}$ & 4.863 & 2.528 & 0.647 & 10.350 & 2.526 \\
\hline $\mathrm{b}$ & 4.829 & 2.524 & 0.662 & 9.240 & 2.232 \\
\hline C & 4.939 & 2.525 & 0.678 & 10.070 & 2.492 \\
\hline$d$ & 4.805 & 2.519 & 0.630 & 9.090 & 2.177 \\
\hline e & 4.905 & 2.519 & 0.654 & 9.060 & 2.215 \\
\hline$f$ & 4.932 & 2.533 & 0.662 & 12.900 & 3.208 \\
\hline g & 4.821 & 2.531 & 0.015 & 7.370 & 1.787 \\
\hline $\mathrm{h}$ & 4.941 & 2.540 & 0.012 & 6.230 & 1.559 \\
\hline i & 4.919 & 2.528 & 0.014 & 7.090 & 1.750 \\
\hline
\end{tabular}

comparing the oil displacement effects of different types of micro-nano materials in unconventional tight sandstone reservoirs on the basis of the geological background and reservoir structure has yet to be conducted (Nassar et al., 2014; Nazari Moghaddam et al., 2015). In addition, relevant experimental data about continental sandstone reservoirs in China are lacking. Therefore, selecting suitable oil-displacing agents for tight sandstone reservoirs with the complex micronano pore throat structure and studying its displacement mechanism are challenging and meaningful.

Nanoparticles have been the subject of the majority of published studies, and their solid form may cause particle aggregation. However, this study focuses on nanofluids, contrasts several micro-nano oil displacement materials, and analyzes their characteristics theoretically. It also summarizes the physical properties and oil displacement behavior in porous media, evaluates the oil displacement effect from multiple factors, and reveals the oil displacement mechanism. This study provides theoretical and experimental basis for the application of nanofluids in unconventional oil reservoirs to enhance oil recovery.

\section{MATERIALS AND METHODS}

\section{Materials}

\section{Core Samples}

The core samples (A-J) used in this study are tight sandstone taken from Yanchang Formation, Ordos Basin, China with characteristics of low porosity, low permeability, and poor cementation. These samples were used for rock characterization experiments, such as electron microscope observation and imbibition experiments. In addition, some man-made tight cores $(a-i)$ composed of quartz sand were used in some experiments to avoid reservoir heterogeneity and
TABLE 2 | Composition of formation brine.

\begin{tabular}{lcccccc} 
Ion & $\mathbf{N a}^{+} / \mathbf{K}^{+}$ & $\mathbf{C a}^{2+}$ & $\mathbf{M g}^{2+}$ & $\mathbf{C l}^{-}$ & $\mathbf{S O}_{\mathbf{4}}{ }^{2-}$ & $\mathbf{H C O}_{\mathbf{3}}{ }^{-2}$ \\
\hline Concentration, mg/L & 9,283 & 3,296 & 468 & 17,462 & 251 & 73
\end{tabular}

stratigraphic interference, and their parameters are shown in Table 1.

\section{Simulated Oil and Water}

Simulated oil used in the experiment is crude oil taken from the oil field with a viscosity of $3.89 \mathrm{mPa} \cdot \mathrm{s}$ at $70^{\circ} \mathrm{C}$ and a density of $0.826 \mathrm{~g} / \mathrm{cm}^{3}$. The salinity of the simulated brine used to stimulate formation water in the experiment is $30,800 \mathrm{mg} / \mathrm{L}$, and its ion content is shown in Table 2.

\section{Oil-Displacing Agents}

A new nanofluid with diphenyl ether surfactants as shell and $\mathrm{C}_{10}-\mathrm{C}_{14}$ straight-chain hydrocarbon compounds as kernel was prepared, and the concentration of the original solution used in following experiments is $35 \%$. Three other oil-displacing agents, betaine, cationic surfactant (cetyl trimethyl ammonium chloride), and anionic surfactant (petroleum sulfonate) with good effect and certain representativeness in previous experiments, were selected for the comparative experiments, and they are all available on the market.

Synthesis of Nanofluid: The diphenyl ether surfactants, $\mathrm{C}_{10}-\mathrm{C}_{14}$ straight-chain hydrocarbon compounds, and remaining water were mixed at an optimal proportion and stirred under low energy conditions $\left(30-400 \mathrm{r} / \mathrm{min}, 20-50^{\circ} \mathrm{C}\right)$ until the mixture was completely dissolved to become a homogeneous solution. The homogeneous solution was diluted to low concentration with deionized water or inorganic salt water to prepare the nanofluid permeation flooding system with a shell-kernel structure. 


\section{Reservoir Characteristics Test}

The tight sandstone reservoir of the Yanchang Formation in the Ordos Basin, China, was selected as the research site, and scanning electron microscopy (SEM) was used to observe the microscopic pore throat structure in the study area. The experimental operations are as follows: 1) High-resolution SEM and double beams of field-emission SEM with image panoramic mosaic technology (MAPS) were used to observe the surface of rock samples and the abundance and form of pores and fractures. In the experiment, the accelerating voltage was $10 \mathrm{kV}$, and the beam current was $40 \mathrm{nA}$, which can effectively identify the micro-nano pores in the reservoir. The scanning area of MPS was $2.48 \mathrm{~mm} \times 2.15 \mathrm{~mm}$, and the resolution was $2048 \times$ 1768. It is composed of $1369(37 \times 37)$ pictures. 2) The rock samples observed using scanning electron microscope mineral quantitative evaluation system (QEMSCAN) were consistent with the samples of MAPS, and QEMSCAN provided the mineral content of the study area. 3) For focused ion beam scanning electron microscopy (FIB-SEM), the surface was marked with the ion gun and plate platinum to protect the target area first; then, three sides of the target area were carved to form an observation pit with a depth of $10-20 \mu \mathrm{m}$ and a width of about two times the width of the target area; finally, automatic denudation imaging was started after repeated corrections (Sun et al., 2016). 3D images of the pore structure were obtained using FIB-SEM to analyze the pore distribution and distinguish different pore types in the sandstone samples. A precise characterization of the microscopic properties of the reservoir can be achieved by using these techniques, and pore volume and pore connectivity were evaluated to determine crude oil flow eventually. The apparatus used included Helios 650 and FEI Quanta 650 from Thermo Fisher Scientific, United States.

\section{Measurement of Physical Properties of Agents \\ Interfacial Tension Tests}

The spinning drop method (Cayias et al., 1975) was used to determine the interfacial tension between crude oil and different oil-displacing agent solutions. The experiment was operated as follows: 1) Four oil-displacing agent samples were prepared at five gradient concentrations of oil-displacing agent solutions and injected into the sample tube of the interfacial tension meter. 2) A small amount of crude oil was injected into the sample cell under the condition that no air bubble exists. 3) The sample cell was placed into a spin-dropping device at $70^{\circ} \mathrm{C}$, the instrument speed $(6000 \mathrm{rpm})$ was adjusted to make the oil drop rotate, and the diameter of the oil drop was elongated under the action of centrifugal force and interfacial tension. 4) The diameter of the oil droplets was measured by video image analysis to obtain the interfacial tension. The apparatus used is a rotating droplet interfacial tensiometer produced by DataPhysics Instruments $\mathrm{GmbH}$, German.

\section{Wettability Alteration Test}

Wettability is an important property of solid surfaces, which is usually characterized by contact angle. The experimental operations are as follows:
1) After heating and drying the core extracted with dichloromethane, the core was cut into 3-4 mm-thick uniform thin sections, and the thin sections were saturated by simulated formation water for later use. 2) The treated thin sections were placed into crude oil for aging at $70^{\circ} \mathrm{C}$ for 7 days, and oil-displacing agents of different concentrations were prepared at the same time. Then, the sections were placed into the agents and reacted at $70^{\circ} \mathrm{C}$ for 7 days. 3) The core sections fixed with water droplets were placed in a quartz ark containing different oil-displacing agents, and the contact angle was measured before and after treatment by using the optical contact angle measuring instrument DSA100 from Krüss, Germany.

\section{Particle Size Measurement}

The oil-displacing agents were prepared into solutions with various concentrations and aged at formation temperature. The oil-displacing agents in different aging time were placed in an ultrasonic device for 10 min to make the particles dispersed and then placed into a size analyzer to test the particle size. The apparatus used was Zeta PALS, a zeta potential and NP size analyzer developed by Malvern, United Kingdom.

\section{Spontaneous Imbibition Experiment}

Man-made cores were selected for the imbibition experiments to avoid the negative influence of differences in the mineral composition and anisotropy of field cores on the results. The permeability of the man-made cores had two ranges of about $0.1 \mathrm{mD}$ and about $1 \mathrm{mD}$. The steps of the experiment are as follows: 1) After measuring the core porosity and permeability parameters required for the experiment, the core (without initial water) was evacuated for $4 \mathrm{~h}$ to remove air and saturate the oil. 2) After aging the saturated-oil cores, we weighted the cores and measured their NMR $\mathrm{T}_{2}$ spectrum. 3) The oil-saturated core was immersed in liquid filled with oildisplacing agents in $70^{\circ} \mathrm{C}$ (Figure 1). The volume of oil removed from the core was monitored over time, with frequent recordings at the initial stage and once every $24 \mathrm{~h}$ afterward. The NMR $\mathrm{T}_{2}$ spectrum was measured again after the imbibition. In addition, a certain concentration of $\mathrm{MnCl}_{2}$ must be added to the water used in the experiment to shield the hydrogen signal in the water and make the NMR results more accurate.

\section{RESULTS}

\section{Characteristics of Reservoir Rock Mineral Composition}

QEMSCAN test results indicate that the minerals with the highest content are quartz, albite, illite, and K-feldspar, which are also the main constituent minerals of tight sandstone reservoirs, and their average mineral proportions can reach 50.86, 13.59 , and 7.34 , and $5.33 \%$, respectively; the contents of mica, calcite, dolomite, and kaolinite followed closely, and their average proportions are distributed between 1 and $4 \%$ (Figure 2). Illite with a high content is a weakly 


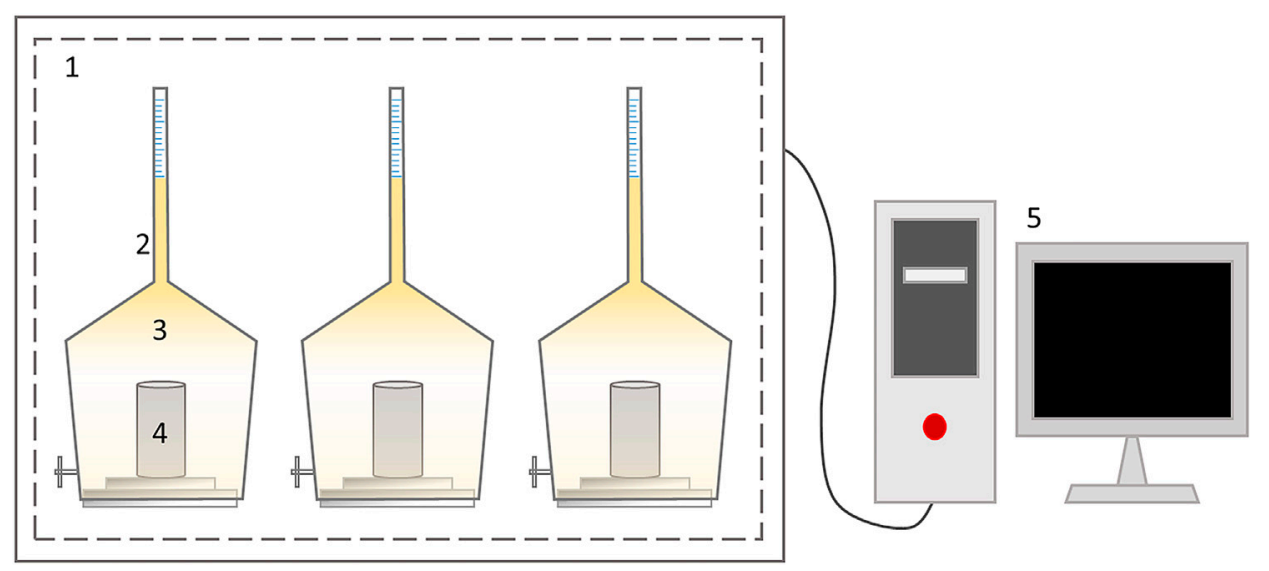

FIGURE 1 | Schematic of the imbibition assembly: (1) temperature control system, (2) imbibition apparatus, (3) oil-displacing agent, (4) core, (5) data entry system.

expansive clay mineral, and its crystal layer is not easy to separate even in the presence of water molecules, thus preventing the throat plugging. Kaolinite is also a relatively stable non-expansive mineral, which has weak adhesion to sandstone particles and is prone to particle migration. Thus, the flow rate of the injected fluid should be controlled. In general, the type, content, and form of minerals affect pore abundance and EOR implementation to some degree.

\section{Pore Throat Structure}

Pore throat structure is relevant to mineralogy, which can be partially explained by the crystalline structure of minerals, as well as practical reservoir conditions like humidity, temperature, and applied stresses (Zhang F. et al., 2020). In addition to clastic particles, organic matter, impurities, and cements, the rock composition of tight sandstone reservoirs also includes many types of pores. SEM observation shows that the reservoir pores in the studied area are underdeveloped with low porosity and the reservoir space can be divided into primary and secondary pores according to genesis. Primary pores include intergranular and intercrystalline pores; secondary pores include intergranular dissolved pores, intragranular dissolved pores, and a few micro-fractures. 1) Intergranular pores: mainly composed of residual intergranular pores, which have regular shape and smooth boundary with a relatively regular shape in triangle or polygon. The average diameters of the pores and throats are $10-50 \mu \mathrm{m}$ (Figures 3A,E). 2) Intercrystalline pores: micropores mainly exist in authigenic clay minerals, such as kaolinite, chlorite, and illite. The small pores are mainly micro-nano-scale with certain connectivity, and their average diameters are generally $0.1-3 \mu \mathrm{m}$ (Figures 3C,D,F,I). 3) Intergranular dissolved pores: caused by the erosion of the edges of debris particles and cements, with irregular shapes and a wide range of pore size distribution. When the dissolution is strong, these pores often communicate with other pores to form super-large composite pores with diameters ranging from 1 to $30 \mu \mathrm{m}$ (Figure 3B). 4) Intragranular dissolved pores: mainly include feldspar dissolved pores and lithic dissolved pores. Feldspar dissolved pores generally develop along joints, and lithic dissolved pores have honeycomb structure, with relatively isolated distribution and poor connectivity. The average pore size distribution is $0.5-3 \mu \mathrm{m}$ (Figure 3G). 5) Micro-fractures: the pores are mainly connected by micro-fractures, such as cracks, joints, and natural deflects abounded in rock material, and closely connected to the rupture, failure, and loss of stability (Li et al., 2017). Its width is generally a few nanometers to tens of nanometers (Figure 3H).

SEM and FIB-SEM results show that the pores in the micronano porous reservoirs are generally small, and the pore diameter is basically below $30 \mu \mathrm{m}$, dominated by $50 \mathrm{~nm}-10 \mu \mathrm{m}$ nanometer-micrometer pores. Intergranular dissolved pores, intragranular dissolved pores, and micro-fractures are relatively well developed, and the pores are comparatively isolated, unevenly distributed, and poorly connected. FIB shows the $3 \mathrm{D}$ perspective of pore throat structure more directly (Figure 4). The characteristics of tight reservoir rocks have resulted in complex oil and gas occurrence and migration mechanisms. The research of microscopic pore throat structure, pore throat types, and mineral composition from the side confirm that injecting a suitable oil-displacing flooding system is necessary and pave the way for the subsequent work of the microscopic oil displacement mechanism in tight sandstone reservoir.

\section{Properties of Oil-Displacing Agents Dispersed Stability}

The particle size distribution range of all the tested oildisplacing agents is at the micro-nano level according to the size measurement. A higher concentration of the agent intensifies Brownian motion of the droplets, which rise the collision probability and slightly increase the initial particle size. As shown in Figure 5, the initial average particle diameters of the nanofluid with the concentrations of $0.1,0.5$ and $0.9 \mathrm{wt} \%$ are respectively $15.7,17.8$ and $25.0 \mathrm{~nm}$. The microemulsion state of the system with a concentration of 0.1 and $0.5 \mathrm{wt} \%$ remains 

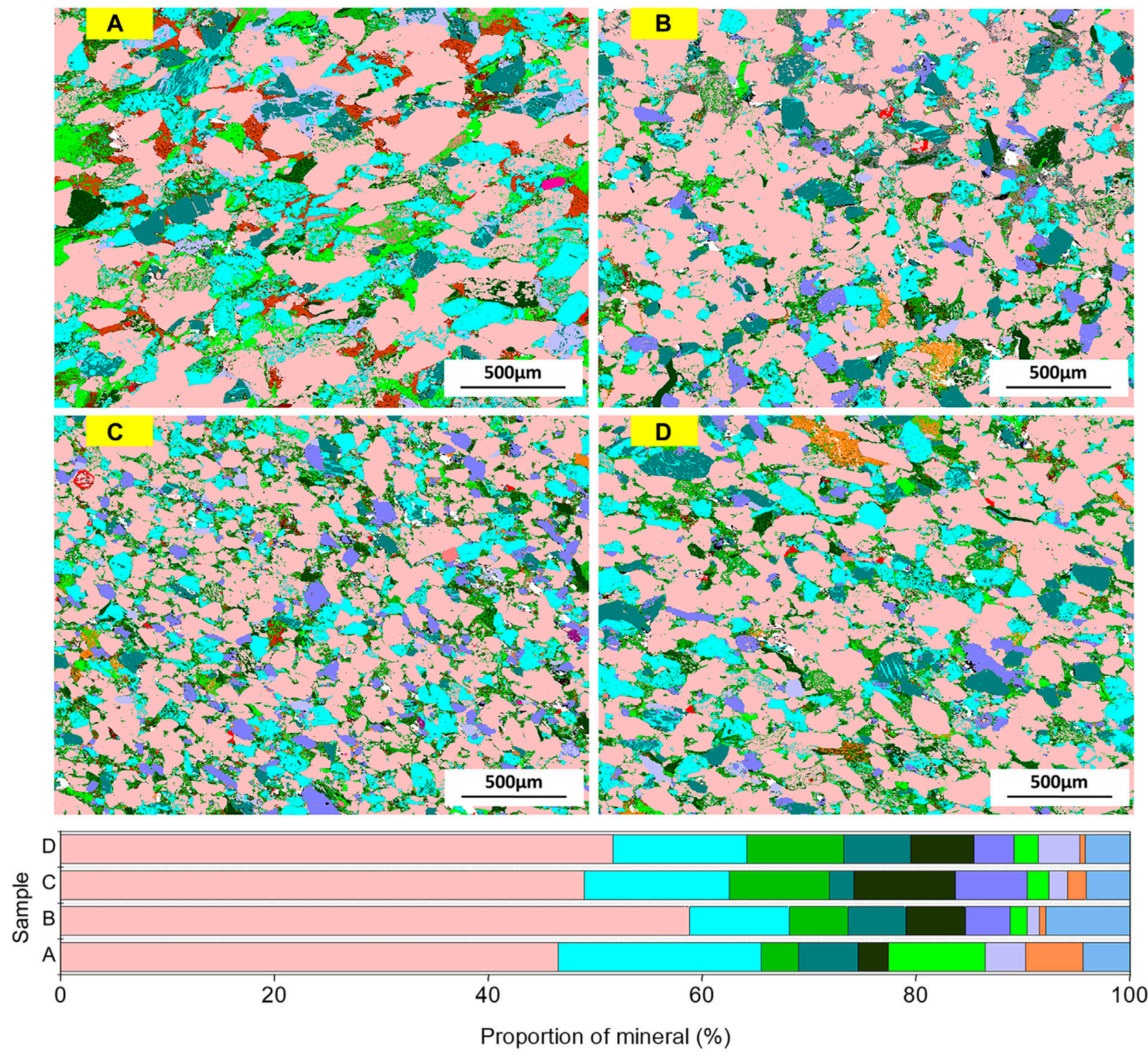

Mineral Name

$\square$ Quartz
$\square$ Albite
$\square$ Illite
$\square$ Dolomite
Muscovite
K-Feldspar
Unclassified

\begin{tabular}{|l}
$\square$ Chlorite \\
$\square$ Pores \\
$\square$ Kaolinite \\
$\square$ Calcite \\
Biotite \\
$\square$ Siderite \\
Rutile
\end{tabular}

$\square$ Smectite
$\square$ Apatite
$\square$ Pyrophyllite
$\square$ Barite
$\square$ Pyrite
$\square$ Ankerite
$\square$ Paragonite

$\mathrm{KCl}$ Mud

Gypsum/Anhydrite

Andesine

Zircon

$\mathrm{NaCl}$ Mud

Anorthite

Unaccounted

FIGURE 2 | Mineral composition of core sample A, B, C and D tested by QEMSCAN.

stable over time, with the average particle size maintain at $20 \mathrm{~nm}$ or so; in a system with a concentration of $0.9 \mathrm{wt} \%$, the particle size increases over time until it reaches equilibrium, and finally stabilizes at about $60 \mathrm{~nm}$. These results indicate that the nanofluid has the greatest advantage over size, and it matches with the small throats very well. The particle of the nanofluid in microemulsion state is relatively stable and dispersible with aging, unaffected by temperature and salinity, which means it can fully adapt to the reservoir conditions. 

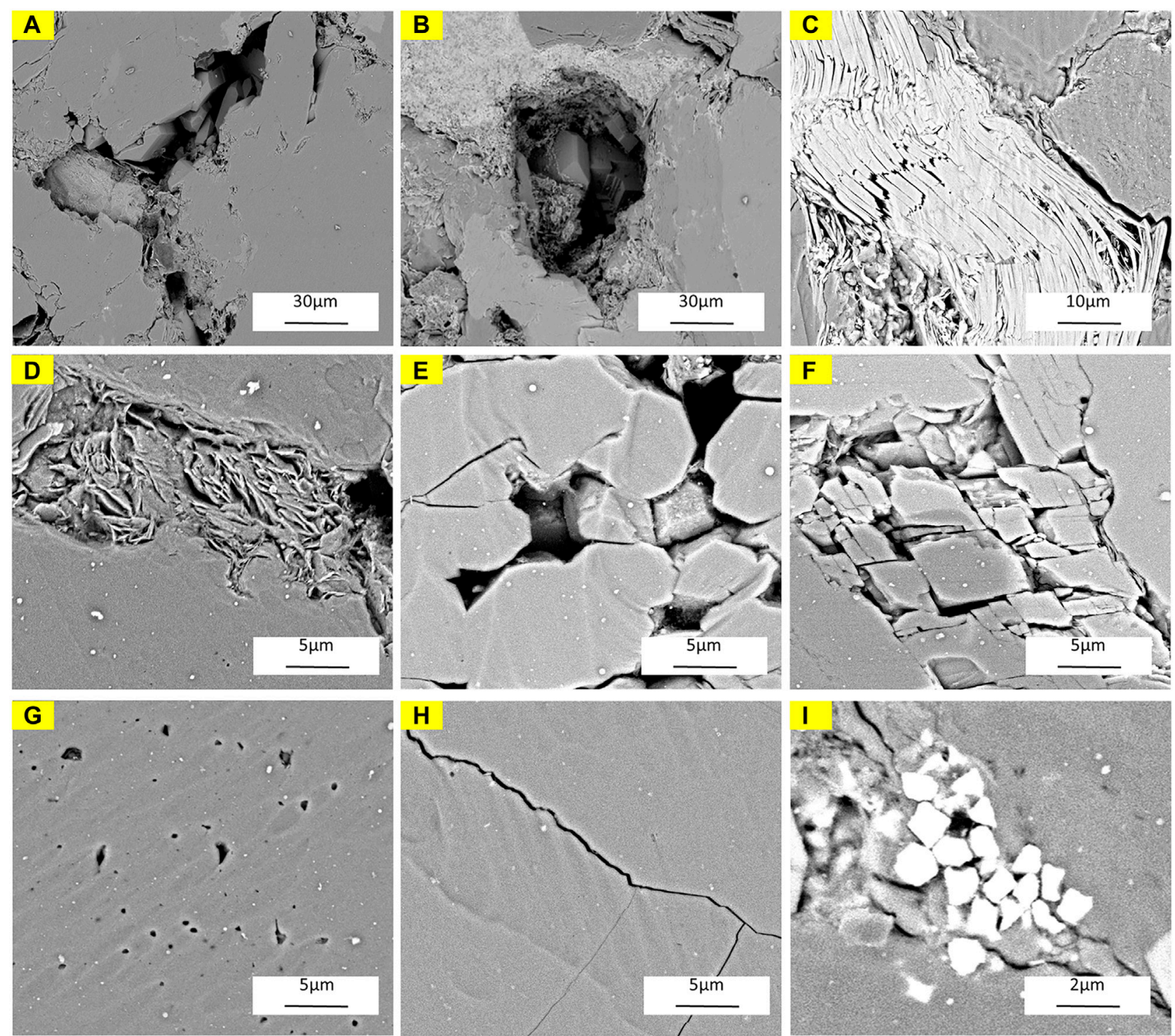

FIGURE 3|Typical SEM photos of pore throat structures: (A) Intergranular pores; (B) Intergranular dissolved pores; (C) Intercrystalline pores (Inter-mica pores); (D)

Intercrystalline pores (Inter-illite pores), (E) Intergranular pores (Inter-quartz-feldspathic pores); (F) Intercrystalline pores (Inter-calcite pores); (G) Intragranular dissolved pores; (H) Micro-fractures; (I) Intercrystalline pores (Inter-pyrite pores).
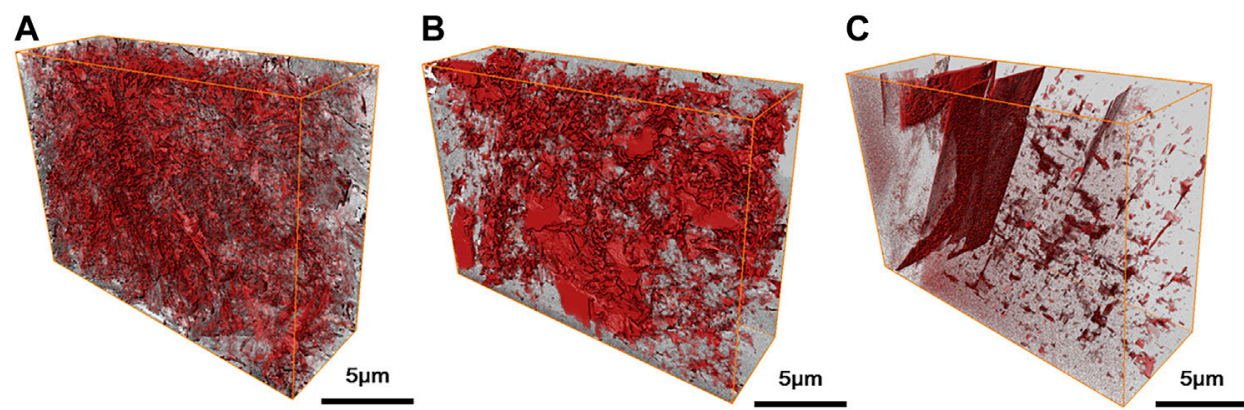

FIGURE 4 | 3D pore throat structure of core sample A, B and C (FIB-SEM). 


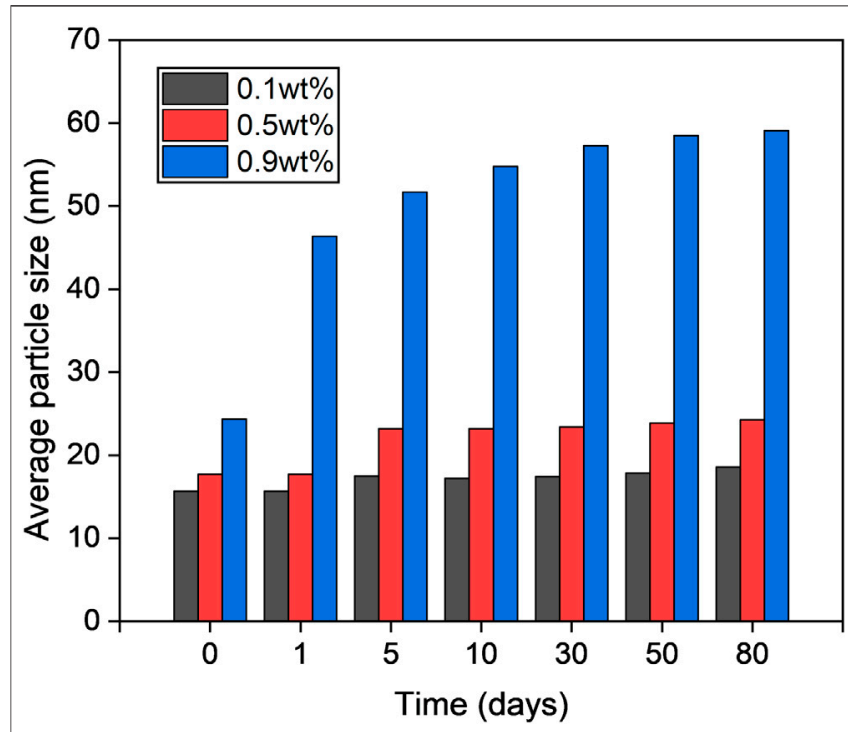

FIGURE 5 | Particle size distribution of the nanofluid at the test temperature of $70^{\circ} \mathrm{C}$.

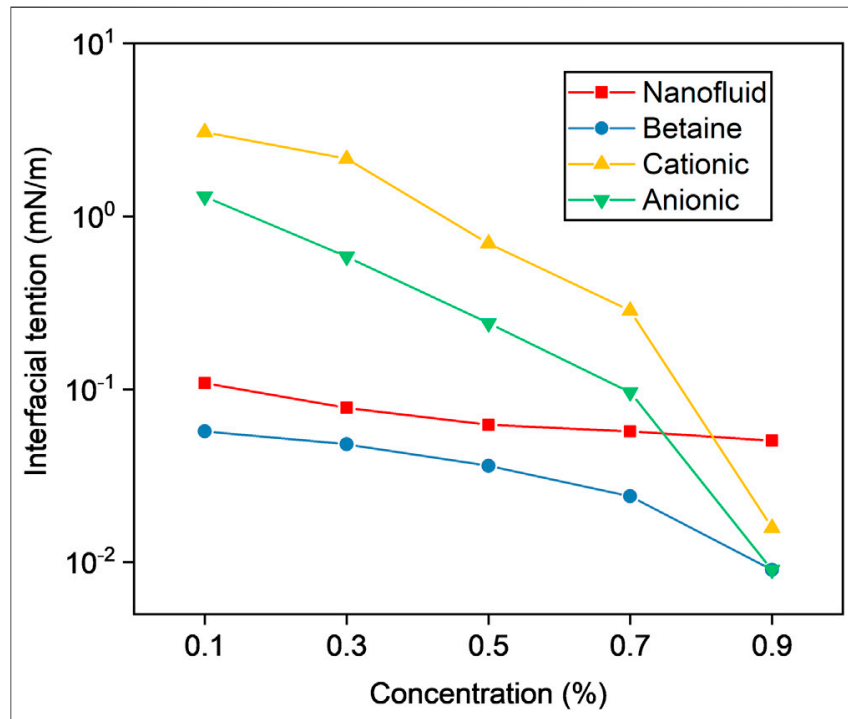

FIGURE 6 | Interfacial tension of four oil-displacing agents with different concentration.

\section{Interfacial Tension}

The interfacial tension test results of the four oil-displacing agents at five concentrations show that the interfacial tension of each oildisplacing agent gradually decreases as the concentration is increased (Figure 6). The cationic surfactant gradually decreases from 3.080 to $0.016 \mathrm{mN} / \mathrm{m}$, and the anionic surfactant gradually decreases from 1.30 to $0.009 \mathrm{mN} / \mathrm{m}$. The low interfacial tension of the cationic surfactant and anionic surfactant could only be maintained at a very high concentration; the line tendency of nanofluid and betaine is flatter and more gently changing, and its values are much lower than those of the

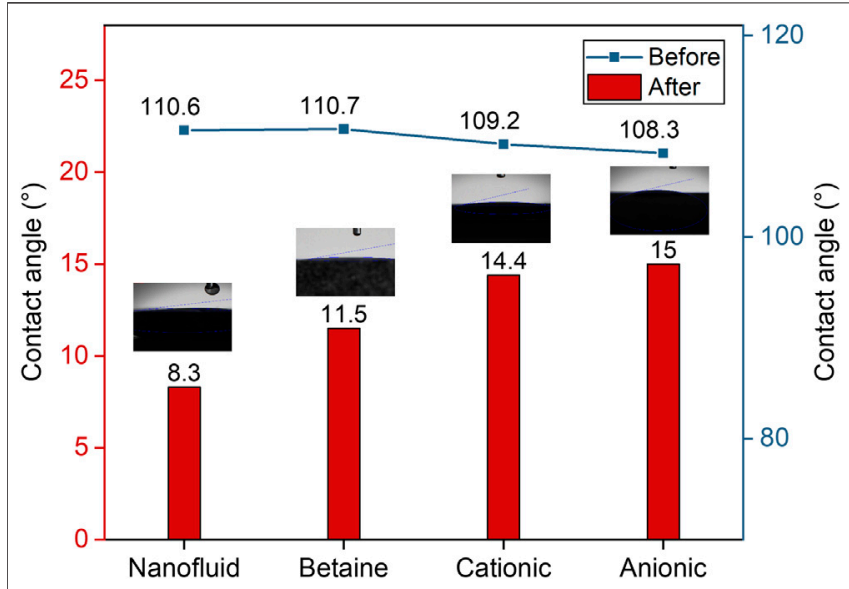

FIGURE 7 | Contact angle before and after oil displacement agent treatment.

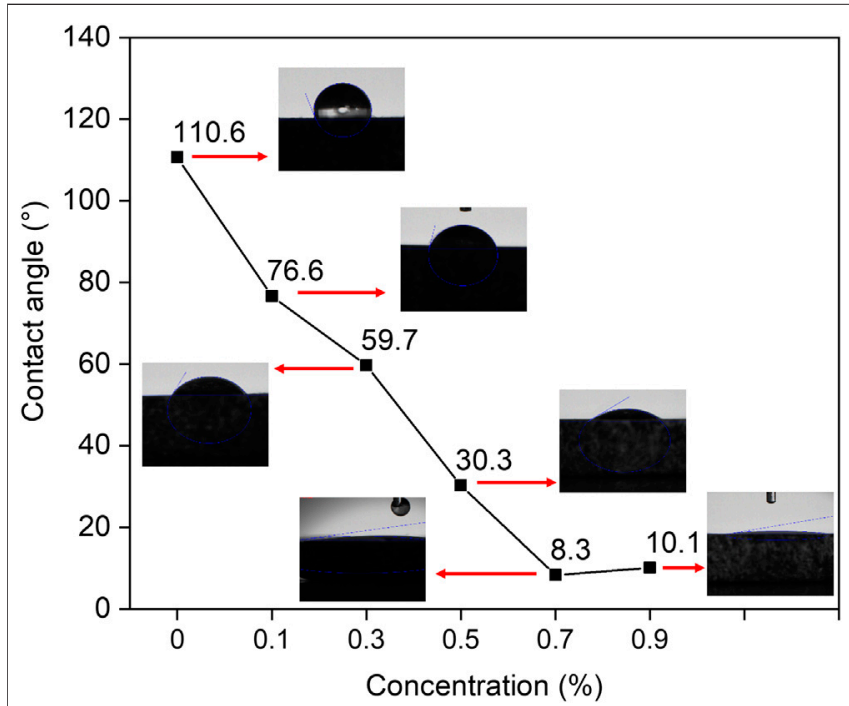

FIGURE 8 | Contact angles in different concentrations of nanofluids.

anionic and cationic surfactants, which range within $1 \times 10^{-2}-1 \times$ $10^{-1} \mathrm{mN} / \mathrm{m}$. After the interfacial tension is in the order of $1 \times 10^{-2}$ $\mathrm{mN} / \mathrm{m}$, the effect of increasing the concentration to reduce the interfacial tension is not obvious.

The decreasing tendency of interfacial tension is not evident in Figure 6 when the concentration is high (0.7 wt\%, $0.9 \mathrm{wt} \%)$. Nevertheless, underground oil-displacing agents are diluted to an extremely low concentration in the practical flooding process, and the high concentration also represent high costs, so ignore the negative effects in high concentrations and control the concentration accurately in a low value.

\section{Wettability Alteration}

Considering the interfacial tension, the nanofluid, betaine, cation surfactant, and anion surfactant have the optimal concentration 


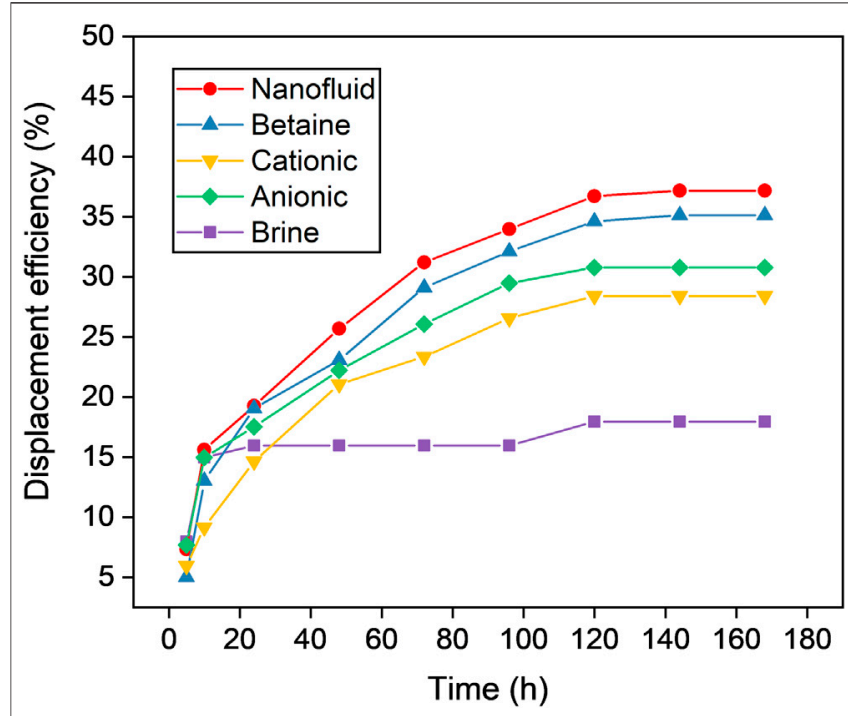

FIGURE 9 | Displacement efficiency of different oil displacement agents (1 mD).

values for wettability modification of $0.5,0.1,0.9$, and $0.7 \mathrm{wt} \%$, respectively. The contact angles of the rock thin sections before and after treatment by the oil-displacing agents and the optimum concentration determined by the interfacial tension of different oil-displacing agents were measured. Figure 7 shows that betaine decreases from the initial $110.7^{\circ}$ to $11.5^{\circ}$, cationic surfactant decreases from the initial $109.2^{\circ}$ to $14.4^{\circ}$, and the anionic surfactant decreases from the initial $108.3^{\circ}$ to $15.0^{\circ}$. As shown in Figure 8, the nanofluid's contact angle of the two phases before treatment is $110.6^{\circ}$, and the contact angle gradually decreases as the concentration is increased, which reaches a minimum of $8.3^{\circ}$ at $0.7 \mathrm{wt} \%$. Then, the contact angle increases slightly as the concentration is increased. Although different oil-displacing agents change the wettability to different degrees, the wettability of the rock interface is reversed from lipophilic to stronghydrophilic after treatment with these four oil-displacing agents.

\section{Oil-displacement Capacity Spontaneous Imbibtion}

All core samples are subject to the spontaneous imbibition test. In different imbibition devices, cores were immersed in different liquid phases. Compared with the contact angle measurement experiment in which only one water droplet is in contact with the outer surface of the core sample, the self-absorption test involves a large amount of water entering the interconnected porous space of the rock and contacting the inner surface of the rock.

The cores used in this experiment are sample $a$, sample $b$, sample $c$, sample $d$, sample $e$ and sample $f$, undergoing imbibition using nanofluid, betaine, cationic surfactant, anionic surfactant, and brine, respectively. The permeabilities of these cores are distributed below $1 \mathrm{mD}(0.64-0.68 \mathrm{mD})$, as shown in Table 2. Figure 9 displays the curve of the spontaneous imbibition displacement efficiency over time. The figure shows that the replacement rate is very high in the initial stage of imbibition, and the displacement efficiency increases rapidly because the core absorbs water and removes oil under the function of capillary force; as time goes by, the water saturation of the core continues to increase, the capillary action weakens, and the imbibition rate gradually slows down until the curve is flat. Ultimately, the cumulative recovery rate does not change after reaching the maximum value. After the imbibition tests, 37.2, $35.1,28.4,34.2$, and $18.0 \%$ of oil are extracted in cores immersed in nanofluid, betaine, cationic surfactant, anionic surfactant, and brine, respectively.

Lines in Figure 10 show the measurement results of the cores with permeability about $0.1 \mathrm{mD}$ (sample $g$, sample $h$ and sample $i$ are used). Only nanofluid and betaine were tested in this experiment because of the poor effects of the cationic and anionic surfactants. The corresponding recovery factors of the nanofluid and betaine systems are 37.5 and $31.3 \%$. Results show that in tight sandstone cores, nanofluid has the best oil displacement effect in the imbibition experiment because of its low interfacial tension and wettability alteration.

\section{NMR $\mathrm{T}_{2}$ Analysis}

The NMR $\mathrm{T}_{2}$ spectra corresponding to different oil-displacing agents in the same permeability interval are drawn to the same coordinate system to elucidate the mechanism, and the changes in the NMR $\mathrm{T}_{2}$ spectrum during imbibition are shown in Figures 11, 12, which further visually verify the total displacement efficiency of the imbibition experiment. Figure 11 shows the crude oil production degree of the $1 \mathrm{mD}$ cores treated by different fluids before and after the imbibition experiment, and Figure 12 shows the results of $0.1 \mathrm{mD}$ cores. Although the curve shape and the corresponding peak value differ during imbibition, their change trends are the same (Lowden et al., 1998; Y; Volokitin et al., 2001). The analysis suggests that the curve characterizes the oil distribution in different cores because $\mathrm{Mn}^{2+}$ shields the hydrogen signal in the water. Therefore, the mechanism of

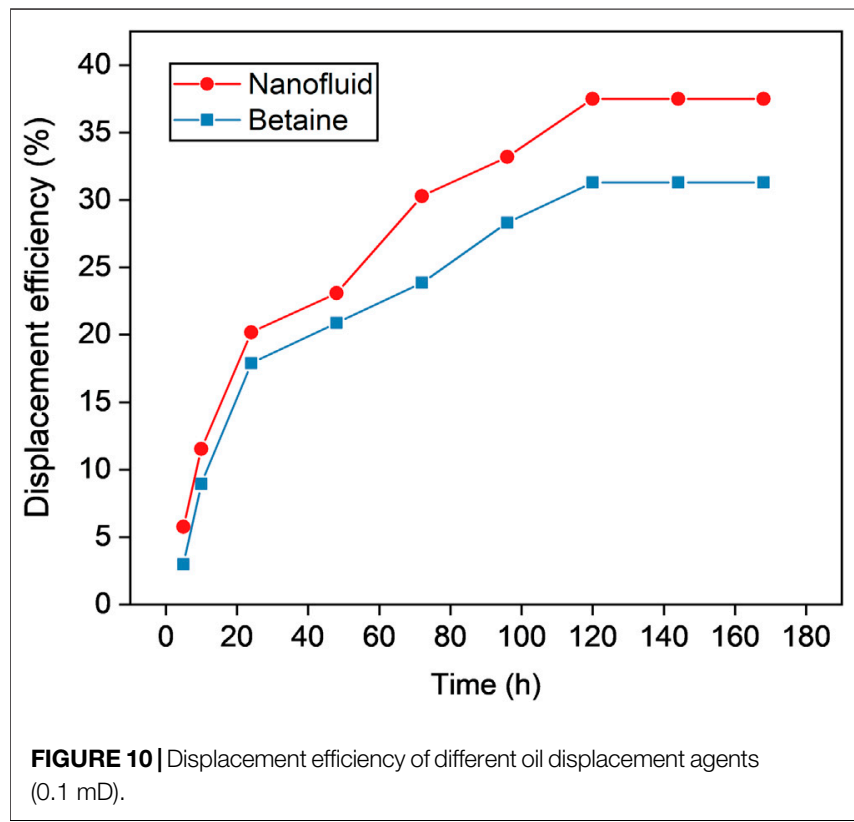




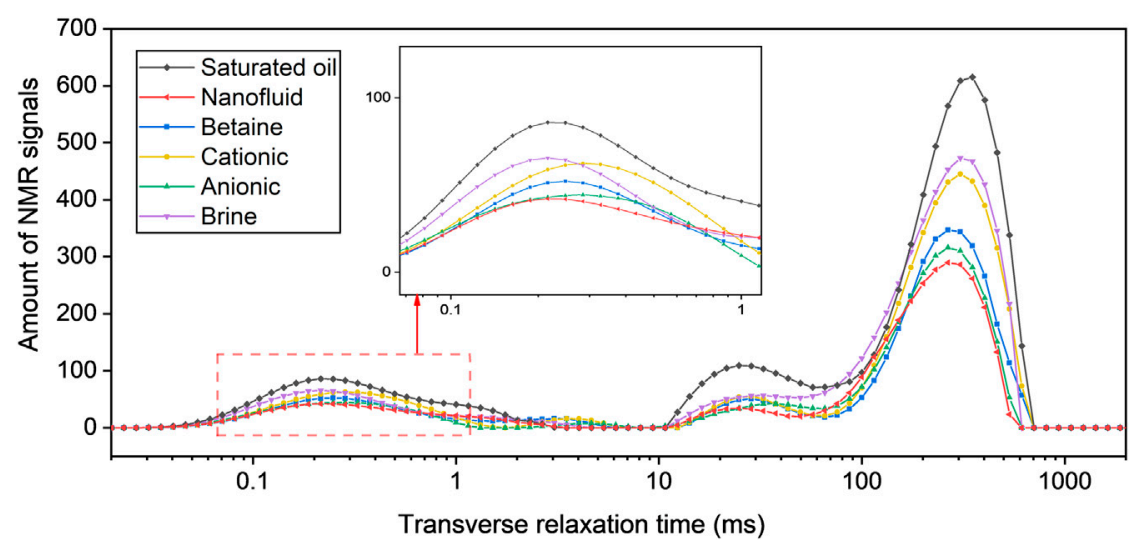

FIGURE 11 | The $T_{2}$ curves of the cores before and after imbibition (1 mD).

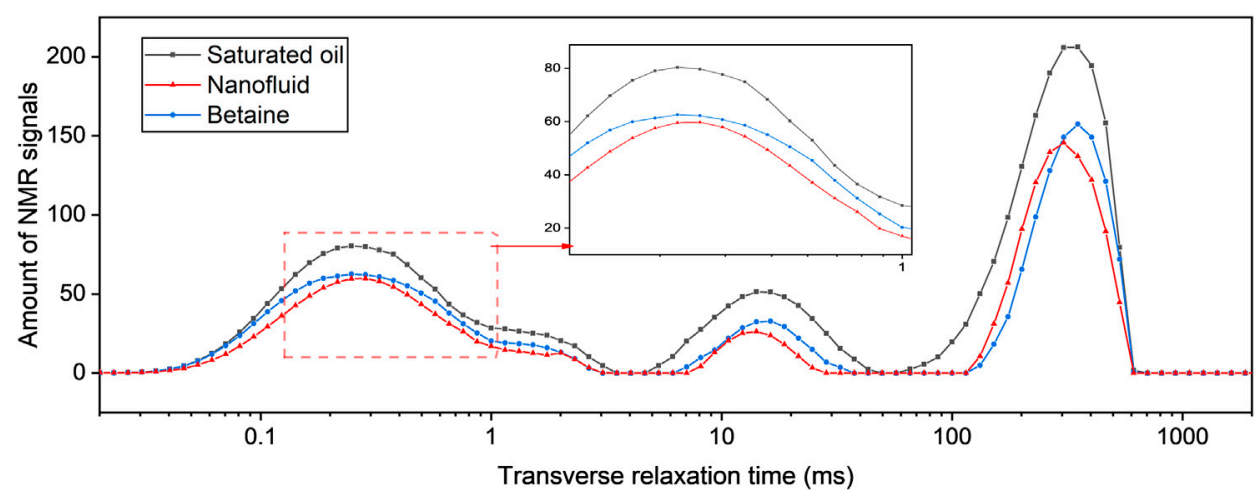

FIGURE 12 | The $T_{2}$ curves of the cores before and after imbibition (0.1 mD).
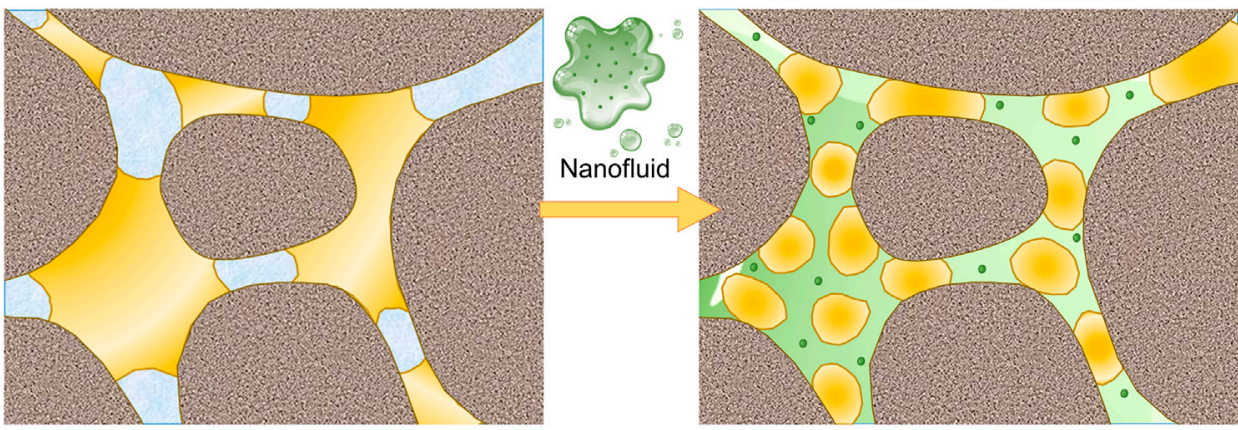

FIGURE 13 | Mechanism of nanofluid's enhancing oil permeation capacity.

imbibition to replace the oil can be understood directly through the changes in the area enclosed by the curve.

The principle is shown in the following formula:

$$
\frac{1}{T_{2}}=\rho_{2} \frac{S}{V}=C \frac{1}{r}
$$

Where $T_{2}$ is the relaxation time indicated by nuclear magnetic resonance, $m s ; \rho_{2}$ is the relaxation rate, $\mu \mathrm{m} / \mathrm{ms} ; \mathrm{S} / \mathrm{V}$ is the pore comparison area, dimensionless; $\mathrm{C}$ is the conversion coefficient, dimensionless, and $\mathrm{r}$ is the pore radius, $\mu \mathrm{m}$.

Therefore, the larger the pore radius, the longer the relaxation time. The NMR $\mathrm{T}_{2}$ spectrum obtained by the experiment shows an obvious multi-peak shape, indicating the presence of small pores $(0.1-1 \mathrm{~ms})$, medium pores $(10-100 \mathrm{~ms})$, and large pores (100-1000 ms) from left to right. The integral area of each curve in the figure represents the total amount of remaining oil, and 
comparing the areas of different sizes pores can directly indicate their contribution to the oil recovery factor of the imbibition test. During the imbibition of the nanofluid acting on the core of $0.1 \mathrm{mD}$ (Figure 12), the total recovery degree is $37.5 \%$, which includes $36.95 \%$ of the large pores' absolute recovery, $62.91 \%$ of the medium pores' absolute recovery, and $32.47 \%$ of the small pores' absolute recovery. The recovery ratio of remaining oil in the medium and small pores is quite considerable, accounting for a certain proportion of the overall recovery rate.

\section{DISCUSSION}

Studies (Zhu et al., 2013) have shown that micro-nano pore space is an important storage space for unconventional oil and gas, and its pore structure is an important factor affecting the physical properties of the reservoir. Precise characterization of the micro-nano pore structure has become an important content of unconventional reservoir research. Several obvious differences exist between tight sandstone reservoirs and conventional oil reservoirs. In specific, sandstone reservoirs have tight lithology, low porosity, and low permeability, especially in the micro-scale with small pore volume, small throat radius, complex connectivity, and heterogeneity. These characteristics cause the mechanism of oil and gas occurrence and migration to be significantly different from those of conventional reservoirs and induce problems such as difficulty in injection and production using generic oil-displacing agents. The size of the pore throat affects the storage performance of tight oil to a certain extent. Figure 13 illustrates the nanofluid's mechanism for increasing oil permeation, which will be explained in following paragraphs.

Because of the oil-displacing agents' characteristic of small size, their transport through the rock near the well bore would be greatly enhanced, allowing the nanofluid to be used for conformance control deeper in the reservoir (Zhang L. et al., 2020). When the concentration of nanofluid exceeds a certain limit, it will cause coalescence and aggregation phenomena, which will rise the particle size into micron range. The agglomerated large-size particles that exceed the pore throat diameter can clog or plug the pore and throat structure, damaging the reservoir. The oildisplacing agent with stable state and good dispersibility can maintain the nano-level particle size, which is beneficial to reduce the injection pressure and allow agent to pass through the small pore throats of tight sandstone reservoirs smoothly. The small particle size also increases the specific surface area of the nanofluid particles and increases the surface activity to provide energy for the oil-water interface better.

The results of interfacial tension experiments show that the use of nano-oil-displacing agents can provide extremely low interfacial tension between the crude oil and oil-displacing agents. In the chemical flooding of tight sandstone reservoirs, the crude oil and the injection flooding system form two-phase seepage in the micronano capillary pores with complex morphology. Oil droplets deform when passing through the capillary pores of reservoirs because of the surface activity acting on the oil-water interface and reducing the oil-water interfacial tension. When the crude oil comes in contact with nanofluids, it is dispersed into smaller oil droplets, thereby reducing the resistance of oil droplets passing through the narrow pore throats and forming a smoother oil displacement system. Therefore, the inference here is that the change in interfacial tension will significantly influence the effect of EOR.

As the main driving factor for imbibition, the capillary effect increases the intrusion capacity of the wetting phase. Tight sandstone reservoirs have small pore throats and high capillary force inversely proportional to the pore size. The contact angle experiment proves that the capillary changes from resistance to driving force when the wettability of the rock surface changes from lipophilic to hydrophilic. It can effectively exert the capillary imbibition effect, allowing the crude oil to peel off easily from the rock formations. As a result, the crude oil continuously peels off during the driving process and is pushed forward by the displacement fluid, which enhances the oil reservoir recovery. The wettability of the rock interface is reversed from lipophilic to strong hydrophilic after being treated with different oil-displacing agents. The change in contact angle is slightly different from the nanofluid to the others, but the overall extent of change is similar. Therefore, the change in wettability promotes the production of crude oil, but it is not a unique oil displacement mechanism for nanofluids.

The results of the imbibition experiment intuitively demonstrate the actual effects of several types of oil-displacing agents. The nanofluid more easily enters the core micro-nano pore throat than the others, and the effect is still excellent under the conditions of ultra-low permeability of $0.1-1 \mathrm{mD}$, which proves that the nanofluid can improve the flow performance of crude oil in the matrix and effectively improve the oil displacement efficiency of the micro-nano pore throat. Moreover, oil-displacing agents enter into cores and displace saturated oil quickly, whereas the imbibition speed of the untreated samples (oil-wet samples) is slow, which concurs with the above-mentioned hydrophilic properties.

$\mathrm{NMR} \mathrm{T}_{2}$ shows that the nanofluid effectively drives a large part of the residual oil in the small pores of tight cores. The small and medium pores play important roles in imbibition, and the medium pores have the highest recovery rate. Although the capillary force, which is the main force of imbibition, is the largest in small pores, the viscous force of the non-wetting phase is also becoming larger, and it leads to a lower recovery rate. Therefore, comprehensively considering the capillary force and the viscous force of the non-wetting phase, the medium pores are more conducive to the progress of imbibition.

Based on the preliminary evaluation of the nanofluid's effectiveness in this paper, we will conduct further studies to explore the undiscovered problems of nanofluids, which involve improving stability, reducing formulation loss underground, and researching more potential oil displacement mechanisms.

\section{CONCLUSION}

This paper discusses the effects of several oil-displacing agents on unconventional tight sandstone reservoirs and explores the potential oil displacement mechanism of nanomaterials under specific reservoir conditions. The following conclusions can be drawn: 
1) The pores and throats of unconventional tight sandstone reservoirs are generally small and not abundant. The reservoir space mainly includes intergranular and intercrystalline pores, intergranular and intragranular dissolved pores, and a small number of fractures. The diameters of main pores and throats are in the range of below $30 \mu \mathrm{m}$, dominated by $50 \mathrm{~nm}-10 \mu \mathrm{m}$ micro-nano pores. Nano oil-displacing agent has good particle size distribution and stable performance, which is beneficial for crude oil to pass nano-pore throats during displacement, and has good matching with the target reservoir pore size distribution. It can effectively enter the nano-scale pore throats in the reservoir matrix. It can also reduce the injection pressure while effectively expanding the swept volume.

2) All four oil-displacing agents can alter the core wettability from lipophilic to strong hydrophilic, and can effectively exert capillary imbibition during the imbibition process, allowing the crude oil to peel off easily from the rock formations. Both nanofluid and betaine have excellent interfacial activity, which can reduce the oil-water interfacial tension reduced to $1 \times$ $10^{-2} \mathrm{mN} / \mathrm{m}$ under the conditions of reservoir temperature and salinity, making the oil droplets easier to deform and disperse into smaller oil droplets when passing through the capillary pore throat, improving the sweep efficiency in the nano throat pore effectively.

3) Imbibition experiments further confirmed the superiority of the newly prepared nanofluid. Compared with other oildisplacing agents, the remaining oil in medium and small pores can be recovered under the simulated condition of tight sandstone reservoirs. In the case of $0.1 \mathrm{mD}$ core, the absolute imbibition efficiency of small pore throat can reach $32.47 \%$, and the total efficiency can reach $37.5 \%$, which shows the great application prospects of this nanofluid.

\section{REFERENCES}

Al-Anssari, S., Ali, M., Alajmi, M., Akhondzadeh, H., and Keshavarz, A. (2021). Synergistic Effect of Nanoparticles and Polymers on the Rheological Properties of Injection Fluids: Implications for Enhanced Oil Recovery. Energy Fuels 35, 6125. doi:10.1021/acs.energyfuels.1c00105

Cayias, J. L., Schechter, R. S., and Wade, W. H. (1975). The Measurement of Low Interfacial Tension via The Spinning Drop Technique. Adsorption at Interfaces 17, 234-247. doi:10.1021/bk-1975-0008.ch017

Chang, H. L., Zhang, Z. Q., Wang, Q. M., Xu, Z. S., Guo, Z. D., Sun, H. Q., et al. (2006). Advances in Polymer Flooding and Alkaline/Surfactant/Polymer Processes as Developed and Applied in the People's Republic of China. J. Pet. Techn. 58, 84-89. doi:10.2118/89175-jpt

Dai, C., Wang, X., Li, Y., Lv, W., Zou, C., Gao, M., et al. (2017). Spontaneous Imbibition Investigation of Self-Dispersing Silica Nanofluids for Enhanced Oil Recovery in Low-Permeability Cores. Energy Fuels 31, 2663-2668. doi:10.1021/ acs.energyfuels.6b03244

Das, S. K., Choi, S., Yu, W., and Pradeep, T. (2008). Nanofluids: Science and Technology. Hoboken, NJ: John Wiley \& Sons.

Ehtesabi, H., Ahadian, M. M., and Taghikhani, V. (2015). Enhanced Heavy Oil Recovery Using TiO2 Nanoparticles: Investigation of Deposition During Transport in Core Plug. Energy Fuels 29, 1-8. doi:10.1021/ ef5015605
This study serves as a reference for tight continental sandstone reservoirs with micro-nano pore throat systems, which are difficult to treat with generic oil-displacing agents. The new nanofluid can act on formation energy replenishment, displacement, cyclic injection, and other technical methods effectively, achieving effective crude oil removal and EOR. The development and utilization of nano-scale oil displacement materials are expected to become a disruptive technology for the efficient production of unrecoverable reserves.

\section{DATA AVAILABILITY STATEMENT}

The original contributions presented in the study are included in the article/Supplementary Material, further inquiries can be directed to the corresponding authors.

\section{AUTHOR CONTRIBUTIONS}

XJ provided the idea of this study and designed the paper framework. J-PT and L-HL investigated 491 the background and proposed the methodology. BD prepared the nanofluid. C-JZ performed experiments, processing, and data analysis, and wrote original draft. Z-JP and S-WM conceptualized and validated the conclusion. BX and $\mathrm{YW}$ provided relevant references and made corrections to the manuscript. All authors contributed to the article and approved the submitted version.

\section{FUNDING}

This work was supported by the National Key Research and Development Program of China (Grant No. 2019YFA0708701).

Ehtesabi, H., Ahadian, M. M., Taghikhani, V., and Ghazanfari, M. H. (2014). Enhanced Heavy Oil Recovery in Sandstone Cores Using TiO2 Nanofluids. Energy Fuels 28, 423-430. doi:10.1021/ef401338c

Fletcher, A., and Davis, J. (2010). "How EOR Can Be Transformed by Nanotechnology," in Spe Improved Oil Recovery Symposium, Tulsa, OK, April 24-28, 2010. doi:10.2118/129531-ms

Giraldo, J., Benjumea, P., Lopera, S., Cortés, F. B., and Ruiz, M. A. (2013). Wettability Alteration of Sandstone Cores by Alumina-Based Nanofluids. Energy Fuels 27, 3659-3665. doi:10.1021/ef4002956

Guo, F., and Aryana, S. (2016). An Experimental Investigation of NanoparticleStabilized CO 2 Foam Used in Enhanced Oil Recovery. Fuel 186, 430-442. doi:10.1016/j.fuel.2016.08.058

Hendraningrat, L. (2013). A Coreflood Investigation of Nanofluid Enhanced Oil Recovery. J. Pet. Sci. Eng. 111, 128. doi:10.1016/j.petrol.2013.07.003

Hendraningrat, L., and Torsæter, O. (2014). Effects of the Initial Rock Wettability on Silica-Based Nanofluid-Enhanced Oil Recovery Processes at Reservoir Temperatures. Energy Fuels 28, 6228-6241. doi:10.1021/ ef5014049

Jay, V., Jim, T., Bob, V., Pitts, M. J., and David, P. (1999). “Alkaline-SurfactantPolymer Flooding of the Cambridge Minnelusa Field," in SPE Rocky Mountain Regional Meeting, Gillette, WY, May 15-18, 1999.

Ju, B., and Fan, T. (2009). Experimental Study and Mathematical Model of Nanoparticle Transport in Porous Media. Powder Techn. 192, 195-202. doi:10.1016/j.powtec.2008.12.017 
Ju, B., Fan, T., and Ma, M. (2006). Enhanced Oil Recovery by Flooding with Hydrophilic Nanoparticles. China Particuol. 4, 41-46. doi:10.1016/s16722515(07)60232-2

Keykhosravi, A., Vanani, M. B., Daryasafar, A., and Aghayari, C. (2021). Comparative Study of Different Enhanced Oil Recovery Scenarios by Silica Nanoparticles: An Approach to Time-dependent Wettability Alteration in Carbonates. J. Mol. Liquids 324, 115093. doi:10.1016/j.molliq.2020.115093

Ledyastuti, M., and Jason, J. (2020). Molecular Dynamics Simulation of Nanocellulose-Oil-Water Interaction in Enhanced Oil Recovery Application. IOP Conf. Ser. Mater. Sci. Eng. 980, 012008. doi:10.1088/1757-899x/980/1/ 012008

Li, Y., Jia, D., Rui, Z., Peng, J., Fu, C., and Zhang, J. (2017). Evaluation Method of Rock Brittleness Based on Statistical Constitutive Relations for Rock Damage. J. Pet. Sci. Eng. 153, 123-132. doi:10.1016/j.petrol.2017.03.041

Liu, H., Jin, X., and Ding, B. (2016). Application of Nanotechnology in Petroleum Exploration and Development. Pet. Exploration Develop. 43, 1107-1115. doi:10.1016/s1876-3804(16)30129-x

Liu, H., Jin, X., Zhou, D., Yang, Q., and Longqiu, L. I. (2018). Potential Application of Functional Micro-nano Structures in Petroleum. Pet. Exploration Develop. 45, 745. doi:10.1016/s1876-3804(18)30077-6

Lowden, B. D., Porter, M. J., and Powrie, L. S. (1998). "T2 Relaxation Time versus Mercury Injection Capillary Pressure: Implications for NMR Logging and Reservoir Characterisation," in 1998 SPE European Petroleum Conference, The Hague, Netherlands, October 20-22, 1998. doi:10.2118/50607-ms

Muggeridge, A., Cockin, A., Webb, K., Frampton, H., Collins, I., Salino, P., et al. (2014). Recovery Rates, Enhanced Oil Recovery and Technological Limits Recovery Rates, Enhanced Oil Recovery and Technological Limits. Philos. Trans. A. Math. Phys. Eng. Sci. 372, 20120320. doi:10.1098/rsta.2012.0320

Nassar, N. N., Hassan, A., and Vitale, G. (2014). Comparing Kinetics and Mechanism of Adsorption and Thermo-Oxidative Decomposition of Athabasca Asphaltenes onto $\mathrm{TiO} 2, \mathrm{ZrO} 2$, and $\mathrm{CeO} 2$ Nanoparticles. Appl. Catal. A Gen. 484, 161-171. doi:10.1016/j.apcata.2014.07.017

Nazari Moghaddam, R., Bahramian, A., Fakhroueian, Z., Karimi, A., and Arya, S. (2015). Comparative Study of Using Nanoparticles for Enhanced Oil Recovery: Wettability Alteration of Carbonate Rocks. Energy Fuels 29, 2111-2119. doi:10.1021/ef5024719

Ragab, A. M. S., and Hannora, A. E. (2015). "An Experimental Investigation of Silica Nano Particles for Enhanced Oil Recovery Applications," in SPE North Africa Technical Conference and Exhibition (Cairo, Egypt: Society of Petroleum Engineers). doi:10.2118/175829-ms

Sadeghpour, A., Pirolt, F., and Glatter, O. (2013). Submicrometer-Sized Pickering Emulsions Stabilized by Silica Nanoparticles with Adsorbed Oleic Acid. Langmuir 29, 6004-6012. doi:10.1021/la4008685

Shamsijazeyi, H., Miller, C. A., Wong, M. S., Tour, J. M., and Verduzco, R. (2014). Polymer-Coated Nanoparticles for Enhanced Oil Recovery. J. Appl. Polym. Sci. 131, 4401-4404. doi:10.1002/app.40576

Sun, L., Wang, X., Jin, X., Jianming, L. I., and Songtao, W. U. (2016). Three Dimensional Characterization and Quantitative Connectivity Analysis of Micro/nano Pore Space. Pet. Exploration Develop. 43, 537. doi:10.1016/ S1876-3804(16)30063-5

Volokitin, Y., Looyestijn, W. J., Sli J Kerman, W., and Hofman, J. P. (2001). A Practical Approach to Obtain Primary Drainage Capillary Pressure Curves from NMR Core and Log Data. Petrophysics 42.
Wasan, D., Nikolov, A., and Kondiparty, K. (2011). The Wetting and Spreading of Nanofluids on Solids: Role of the Structural Disjoining Pressure. Curr. Opin. Colloid Interf. Sci. 16, 344-349. doi:10.1016/j.cocis.2011.02.001

Zhang, F., An, M., Zhang, L., Fang, Y., and Elsworth, D. (2020a). Effect of Mineralogy on Friction-Dilation Relationships for Simulated faults: Implications for Permeability Evolution in Caprock Faults. Geosci. Front. V. 11, 79-90. doi:10.1016/j.gsf.2019.05.014

Zhang, H., Nikolov, A., and Wasan, D. (2014). Enhanced Oil Recovery (EOR) Using Nanoparticle Dispersions: Underlying Mechanism and Imbibition Experiments. Energy Fuels 28, 3002-3009. doi:10.1021/ef500272r

Zhang, H., Ramakrishnan, T. S., Nikolov, A., and Wasan, D. (2018). Enhanced Oil Displacement by Nanofluid's Structural Disjoining Pressure in Model Fractured Porous media. J. Colloid Interf. Sci. 511, 48-56. doi:10.1016/j.jcis.2017.09.067

Zhang, H., Ramakrishnan, T. S., Nikolov, A., and Wasan, D. (2016). Enhanced Oil Recovery Driven by Nanofilm Structural Disjoining Pressure: Flooding Experiments and Microvisualization. Energy Fuels 30, 2771-2779. doi:10.1021/acs.energyfuels.6b00035

Zhang, L., Abbaspourrad, A., Parsa, S., Tang, J., Cassiola, F., Zhang, M., et al. (2020b). Core-Shell Nanohydrogels with Programmable Swelling for Conformance Control in Porous Media. ACS Appl. Mater. Inter. 12, 34217-34225. doi:10.1021/acsami.0c09958

Zhu, R., Bai, B., and Cui, J. (2013). Research Advances of Microstructure in Unconventional Tight Oil and Gas Reservoirs. J. Palaeogeogr 15, 615-623. doi:10.7605/gdlxb.2013.05.049

Zou, C., Zhai, G., Zhang, G., Wang, H., Zhang, G., Li, J., et al. (2015). Formation, Distribution, Potential and Prediction of Global Conventional and Unconventional Hydrocarbon Resources. Pet. Exploration Develop. 42, 14-28. doi:10.1016/s1876-3804(15)60002-7

Zou, C., Zhu, R., Wu, S., Yang, Z., Tao, S., Yuan, X., et al. (2012). Types, Characteristics, Genesis and Prospects of Conventional and Unconventional Hydrocarbon Accumulations: Taking Tight Oil and Tight Gas in China as an Instance. Acta Petrol. Sin. 33, 173-187. doi:10.7623/syxb201202001

Conflict of Interest: Authors C-JZ, XJ, J-PT, Z-JP, S-WM, BD, YW, and BX were employed by the company PetroChina.

The remaining authors declare that the research was conducted in the absence of any commercial or financial relationships that could be construed as a potential conflict of interest.

Publisher's Note: All claims expressed in this article are solely those of the authors and do not necessarily represent those of their affiliated organizations, or those of the publisher, the editors and the reviewers. Any product that may be evaluated in this article, or claim that may be made by its manufacturer, is not guaranteed or endorsed by the publisher.

Copyright $(2021$ Zhang, Jin, Tao, Xiong, Pan, Meng, Ding, Wang and Liang. This is an open-access article distributed under the terms of the Creative Commons Attribution License (CC BY). The use, distribution or reproduction in other forums is permitted, provided the original author(s) and the copyright owner(s) are credited and that the original publication in this journal is cited, in accordance with accepted academic practice. No use, distribution or reproduction is permitted which does not comply with these terms. 